\title{
Metabolic Changes Preceding Exercise-induced Bronchoconstriction
}

\author{
M. SILVERMAN, SANDRA D. ANDERSON, S. R. WALKER
}

British Medical fournal, 1972, 1, 207-209

\section{Summary}

Five asthmatics aged 25-30 were studied during bicycle ergometer and treadmill exercise. Metabolic and ventilatory changes during exercise were compared with the degree of bronchoconstriction which followed exercise. In all patients bronchoconstriction was greater after treadmill exercise. Contrary to previous suggestions, exercise-induced bronchoconstriction did not seem to be caused by lactic acidosis, increase in minute ventilation, acidaemia, hypocapnia, or change in arterial Po.

\section{Introduction}

Exercise-induced bronchoconstriction is an increasingly recognized symptom of asthma. Recent investigations have not elucidated the mechanism whereby exercise provokes bronchoconstriction. Some of the factors thought to be important in explaining the mechanism include increased minute ventilation (Herxheimer, 1946; Irnell and Swartling, 1966; Rebuck and Read, 1968; Ferguson et al.. 1969; Stanescu and Teculescu, 1970), hypocapnia (Herxheimer, 1946; Ferguson et al., 1969; Fisher et al.. 1970: Stanescu and Teculescu, 1970), acidaemia (Seaton et al., 1969), abnormalities of "oxygen transport" (Katz et al., 1971), and lactic acidosis (Seaton et al., 1969; Fisher et al., 1970).

Recent investigations in this laboratory have shown that running provokes more severe exercise-induced bronchoconstriction than does cycling at an equivalent oxygen consumption and heart rate (Anderson et al., 1971). Therefore the present study was carried out to see whether the metabolic and ventilatory changes which occur during these two forms of exercise were in any way related to the degree of bronchoconstriction provoked by the exercise. By using each subiect as his own control we have been able to overcome the limitations of previous studies in which either no form of control was used or the control group was not strictly comparable with the experimental group.

\section{Patients and Methods}

Four men and one woman aged 25-30 years, of average height and weight, who had recently been inpatients at the Brompton Hospital, were studied. They all had asthma as defined by Scadding (1966), and exercise-induced bronchoconstriction had been provoked during previous tests in this laboratory. A detailed history was taken from each patient, and before both studies a careful explanation of the tests was given and consent was obtained in writing.

No patient had taken bronchodilator drugs or disodium cromoglycate within 12 hours or antihistamines within 24 hours of any test. Corticosteroid treatment was continued in Cases 2 and 4. Each patient performed two exercise tests (Lode

Institute of Diseases of the Chest, Brompton Hospital, London S.W.3 M. SILVERMAN, M.B., B.CHIR., M.R.C.P., Clinical Lecturer SANDRA D. ANDERSON, B.SC., Research Assistant

S. R. WALKER, PH.D., Lecturer bicycle ergometer and Quinton treadmill) of identical duration on different days. The order in which the tests were performed was randomized. Spirometry and peak expiratory flow rate (PEFR) were measured at rest; studies were carried out only if values were similar to those obtained before previous tests. Before each exercise test a flexible plastic cannula was placed in the brachial artery under local anaesthesia. Measurements were then made at rest of heart rate and minute ventilation, and an arterial blood sample $(4 \mathrm{ml})$ was collected simultaneously in a heparinized syringe. Blood $(2 \mathrm{ml})$ was pipetted into $0.6 \mathrm{M}$ perchloric acid $(2 \mathrm{ml})$ and lactate levels were estimated by utilizing a nicotinamide-adenine-dinucleotide/ lactate-dehydrogenase system, the measurements being carried out spectrophotometrically (Unicam spectrophotometer S.P. 500 ). Blood gas tensions and $\mathrm{pH}$ were measured with Eschweiler microelectrodes on the remainder of the sample. PEFR was measured (Fleisch pneumotachygraph) and exercise begun.

On the basis of tests carried out previously a work load was chosen for the first study which would produce a heart rate of at least 160 beats/minute. For the second study a load was used which was estimated to produce the same heart rate, oxygen consumption, and minute ventilation as in the first study. During exercise the patients breathed through a lowresistance valve of low dead space $(53 \mathrm{ml})$. Measurements of heart rate, minute ventilation, arterial blood gases $\left(\mathrm{PCO}_{2}, \mathrm{Po}_{2}\right)$, $\mathrm{pH}$, lactate, and PEFR were made every two minutes during exercise and at increasing intervals after exercise. Expired gas was flushed continuously through a Tissot spirometer and analysed for $\mathrm{CO}_{2}$ (URAS-4) and $\mathrm{O}_{2}$ (Servomex). All data were displayed on a chart recorder (Mingograf 81 ). The duration of exercise was six or eight minutes and was constant in any one patient, and measurements were made for 30-50 minutes after exercise.

The fall in PEFR was calculated as:

$$
\frac{\text { Initial PEFR - lowest PEFR }}{\text { Initial PEFR }} \times 100 \%
$$

whether the lowest value of PEFR occurred during or after exercise.

\section{Results}

Rest.-There were no significant differences as shown by a paired $t$ test between the values at rest for PEFR, arterial $\mathrm{pH}$, $\mathrm{PCO}_{2}, \mathrm{PO}_{2}$, and lactate before the two studies. The pattern of changes in several measurements before, during, and after six minutes of exercise in Case 2 is shown in the Chart.

Exercise.-Individual measurements recorded in the Table were, with the exception of fall in PEFR, made during the last minute of exercise. Arterial blood lactate was higher during bicycle exercise in all patients, whereas arterial pH values were similar for each patient during the two tests. There were no statistically significant differences in arterial $\mathrm{PCO}_{2}$ and $\mathrm{PO}_{2}$ or minute ventilation between the two tests, despite the fact that in four out of the five patients the $\mathrm{PcO}_{2}$ was lower and the $\mathrm{Po}_{2}$ higher during bicycle exercise. Only in Case 3 was the minute ventilation higher during treadmill exercise. In relation to oxygen consumption the minute ventilation on both forms of exercise was normal in three patients; Cases 2 and 5 showed considerable hyperventilation during both types of exercise.

After Exercise.-Representative metabolic and ventilatory 
Metabolic Measurements during the Last Minute of Exercise and Fall in PEFR after Exercise

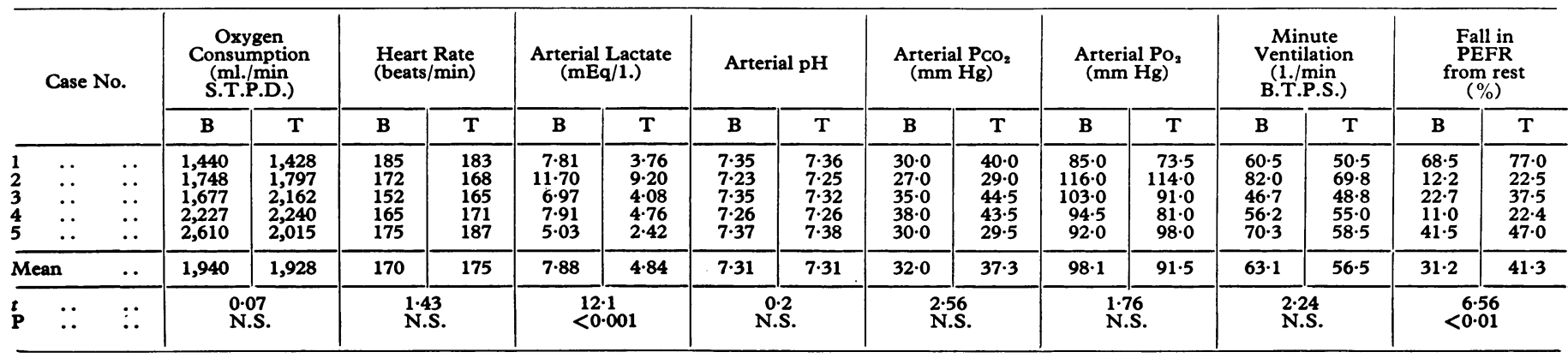

$\mathbf{B}=$ Bicycle ergometer exercise. $T=$ Treadmill exercise. $t=$ Value of Student's $t$ from paired $t$ test. $P=$ Significance of difference between bicycle and treadmill tests. N.S. $=$ P $>0.05$.

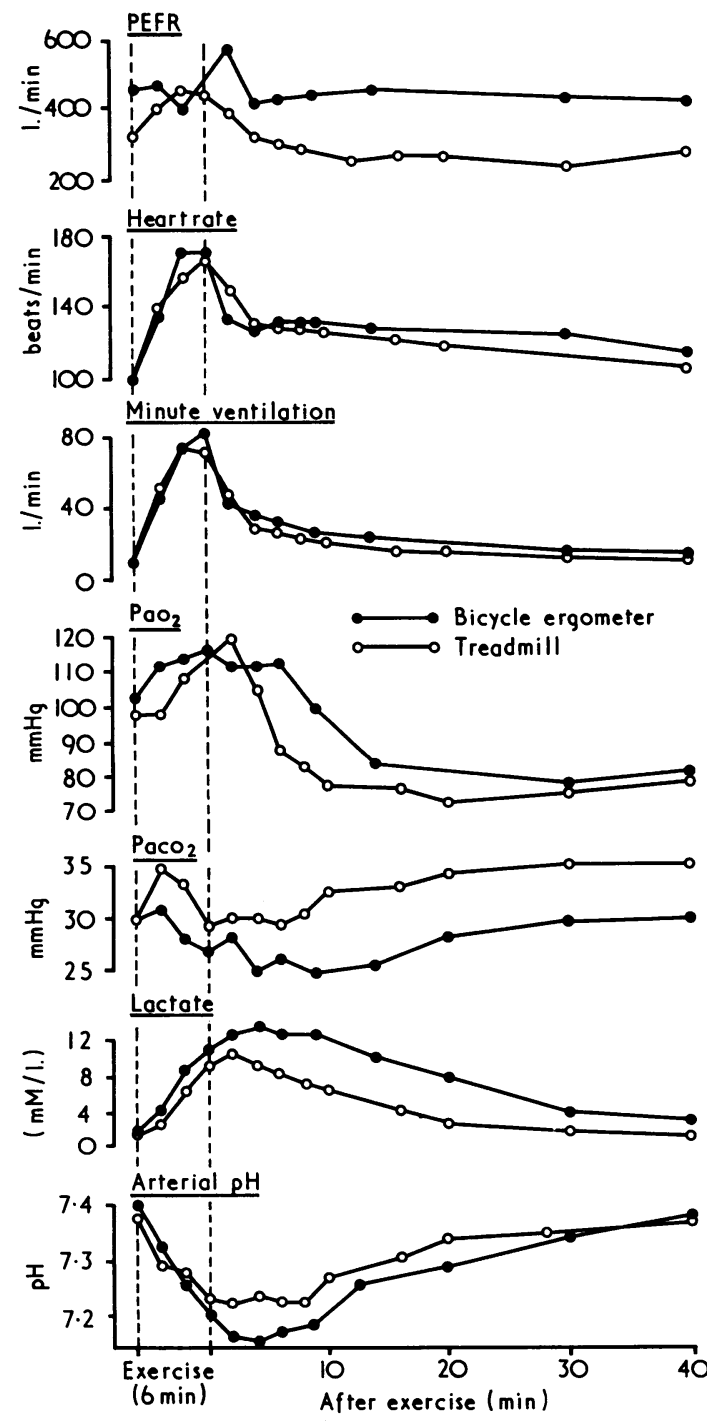

Metabolic and ventilatory changes during and after exercise in Case 2.

changes after exercise are illustrated in the Chart and will be reported in detail elsewhere. Bronchoconstriction (fall in PEFR of more than $15 \%$ from the resting value) occurred after treadmill exercise in all patients, but in only three after bicycle exercise. The fall in PEFR was always greater after treadmill exercise (see Table).

\section{Discussion}

Whereas exercise-induced bronchoconstriction was greater after treadmill exercise, confirming earlier reports from this laboratory (Anderson et al., 1971), lactic acidosis, minute ventilation, hypocapnia, and arterial $\mathrm{Po}_{2}$ were generally greater during bicycle exercise. Arterial $\mathrm{pH}$ was similar during both forms of exercise. Hence the bronchoconstriction after exercise in the present study cannot simply be explained by lactic acidosis, acidaemia, hypocapnia, increase in minute ventilation, or change in oxygen tension during exercise.

The difference in response to the two forms of exercise was not due to any systematic differences in the patients' clinical condition at the start of each study, nor can it be explained by differences in work load (as measured by oxygen consumption and heart rate) during exercise (see Table).

The use of PEFR to assess changes in airway resistance after exercise has recently been justified (Anderson et al., 1972).

Lactate.-The blood lactate levels observed during bicycle exercise in the present study were higher than those reported for normal subjects working at the same oxygen consumption (Hansen et al., 1967; Wasserman et al., 1967) and were appropriate for normal subjects performing a "heavy load" (oxygen consumption $2.51 . / \mathrm{min}$ ). In spite of the higher blood lactate levels the bronchoconstriction after bicycle exercise was less than that after treadmill exercise, when only Case 2 had an abnormally raised lactate level (Hermanson and Saltin, 1969). Two patients with high lactate levels had a fall in PEFR of less than 15\%. Thus the suggestion (Seaton et al., 1969; Fisher et al., 1970) that lactic acidosis may be responsible for exercise-induced bronchoconstriction does not seem to be supported by the results of the present study.

Minute Ventilation, $\mathrm{PaCO}_{2}, \mathrm{pH}$.- It has been proposed that exercise-induced brochoconstriction may be a response to the increased minute ventilation of exercise (Irnell and Swartling, 1966; Rebuck and Read, 1968; Fisher et al., 1970; Stanescu and Teculescu, 1970). The present study shows on the contrary that though minute ventilation was generally greater during bicycle exercise, the bronchoconstriction was greater after treadmill exercise. Differences in minute ventilation between these two forms of exercise may be explained by the greater respiratory drive induced by lactic acidosis on the bicycle ergometer. During bicycle exercise the lower arterial $\mathrm{PCO}_{2}$ found in four patients can be explained by the relative hyperventilation. Though extreme hypocapnia has been shown to cause an increase in airways resistance in man (Newhouse et al., 1964; Sterling, 1968), the present study does not support the theory that moderate hypocapnia (to a level of $27.0 \mathrm{~mm} \mathrm{Hg}$ ) could be a cause of exercise-induced bronchoconstriction (Fisher et al., 1970). Metabolic acidosis after exercise has been thought to induce bronchoconstriction either by causing the release of bronchoconstrictor substances or by blocking natural bronchodilating mechanisms (Seaton et al., 1969). The decrease in $\mathrm{pH}$ in the present study was the same during bicycle and treadmill exercise (see Table) and therefore it cannot be the sole cause of exercise-induced bronchoconstriction. 
Oxygen Tension.-We were unable to confirm the recent suggestion (Katz et al., 1971) that "oxygen transport" may be limited in subjects who develop exercise-induced bronchoconstriction. Though there was a higher arterial $\mathrm{Po}_{2}$ during bicycle exercise in four patients, the mean arterial oxygen saturation did not fall below $96 \%$ in either study. In Case 1, in which oxygen saturation fell to $93.3 \%$ during treadmill exercise, the PEFR had also fallen (from 550 to $4051 . / \mathrm{min}$ ) during the last two minutes of exercise. In the other patients, whose PEFR did not fall during exercise, the small differences in arterial $\mathrm{Po}_{2}$ may be explained by relative hyperventilation during bicycle exercise, as discussed earlier. Arterial hypoxaemia, which has been reported after exercise in patients who develop exercise-induced bronchoconstriction, is likely to be the result of bronchoconstriction rather than its cause (Rebuck and Read, 1968).

\section{Conclusion}

As a result of the present study we are unable to propose any single factor which is responsible for the difference in exercise-induced bronchoconstriction after treadmill and bicycle exercise. We must speculate, as before (Anderson et al., 1971), that neuromuscular effects arising from the mechanical difference between the two forms of exercise may be responsible for the difference in exercise-induced broncho- constriction, either alone or in combination with other variables.

We are grateful to Dr. Margaret Turner-Warwick; the patients in this study were under her care. M.S. and S.D.A. were supported financially by Fisons Pharmaceuticals Limited.

\section{References}

Anderson, S. D., Connolly, N., and Godfrey, S. (1971). Thorax, 26, 396 Anderson, S. D., McEvoy, J. D. S., and Bianco, S. (1972). American Review

of Respiratory Diseases. In press.
Ferguson, A., Addington, W. W., and Gaensler, E. A. (1969). Annals of Internal Medicine, 71, 1063.

Fisher, H. K., Holton, P., Buxton, R. St. J., and Nadel, J. A. (1970). American Review of Respiratory Diseases, 101, 885

Hansen, J. E., Stelter, G. P., and Vogel, J. A. (1967). Fournal of Applied Physiology, 23, 523 .

Hermanson, L., and Saltin, B. (1969). Fournal of Afplied Physiology, 26, 31. Herxheimer, H. (1946). Lancet, $1,83$.

Irnell, L., and Swartling, S. (1966). Scandinavian fournal of Respiratory

Diseases, 47, 103.
Katz, R. M., Whipp, B. J., Heimlich, E. M., and Wasserman, K. (1971). fournal of Allergy, $47,148$.

Newhouse, M. T., Becklake, M. R., Macklem, P. T., and McGregor, M. (1964). Fournal of Applied Physiology, 19, 745.

Rebuck, A. S., and Read, J. (1968). Lancet, 2, 429.

Scadding, J. G., (1966). Lancet, 1, 701.

Seaton, A., Davies, G., Gaziano, D., and Hughes, R. O. (1969). British Medical fournal, 3, 556.

Stanescu, D. S., and Teculescu, D. B. (1970). Respiration, 27, 377.

Sterling, G. M. (1968). Clinical Science, 34, 277

Wasserman, K., Van Kessel, A. L., and Burton, G. (1967). Fournal of Applied Physiology, 22, 71.

\title{
Hypergastrinaemia in Chronic Renal Failure
}

\author{
M. G. KORMAN, M. C. LAVER, J. HANSKY
}

British Medical fournal, 1972, 1, 209-210

\section{Material and Methods}

Fasting serum was obtained from 89 patients with various types of renal disease. The degree of impairment of renal function was arbitrarily classified in relation to the serum creatinine-namely, normal function (serum creatinine $<1 \cdot 2$ $\mathrm{mg} / 100 \mathrm{ml})$, mild impairment $(1 \cdot 2-3.0 \mathrm{mg} / 100 \mathrm{ml})$, and severe impairment $(>3.0 \mathrm{mg} / 100 \mathrm{ml})$. The distribution of the underlying renal disease and the mean age of patients in relation to impairment of renal function is shown in Table $I$.

TABLE I-Distribution of Type of Renal Disease and Mean Age in Relationship to Serum Creatinine Level in 89 Patients

\begin{tabular}{|c|c|c|c|}
\hline & \multicolumn{3}{|c|}{ Serum Creatinine $(\mathrm{mg} / 100 \mathrm{ml})$} \\
\hline & $<1.2$ & $1 \cdot 2-3 \cdot 0$ & $>3.0$ \\
\hline $\begin{array}{lll}\text { Glomerulonephritis } & \ldots & \ldots \\
\text { Renal allografts } & \ldots & \\
\text { Other renal diseases } \\
\text { Age in years (mean } \pm \text { S.D.)... }\end{array}$ & $\begin{array}{l}17 \\
12 \\
0 \\
31 \pm 12 \cdot 6\end{array}$ & $\begin{array}{l}14 \\
19 \\
1 \\
33 \pm 13 \cdot 5\end{array}$ & $\begin{array}{r}16 \\
2 \\
8 \\
35 \pm 12 \cdot 1\end{array}$ \\
\hline
\end{tabular}

Eight patients (mean age 36 years) on chronic maintenance haemodialysis were also studied and fasting serum gastrin levels were compared before and after a 14-hour Kiil haemodialysis.

Serum creatinine, urea, and calcium were determined by standard methods and serum gastrin was measured by radioimmunoassay (Hansky and Cain, 1969; Hansky et al., 1971). The normal range is $0-120 \mathrm{pg} / \mathrm{ml}$.

Basal gastric acid secretion was measured by using the method of Kay (1953).

Statistical comparison of groups was by "Student's" $t$ test, and a $\chi^{2}$ was constructed to compare normal and abnormal

Melbourne University Department of Medicine, Royal Melbourne Hospital, Melbourne, Australia

M. C. LAVER, M.R.A.C.P., Fellow in Renal Medicine 